\title{
Radiolytic and Thermal Processes Relevant to Dry Storage of Spent Nuclear Fuels
}

(Project Number: 60392)

\section{Principal Investigator}

Dr. Steven C. Marschman

Pacific Northwest National Laboratory

P.O. Box 999, MSIN P7-27

Richland, WA 99352

(509) 376-3569 (phone)

steve.marschman@pnl.gov

\section{Co-Investigators}

Prof. Theodore E. Madey

Rutgers University, Dept. of Physics

136 Frelinghuysen $\mathrm{Rd}$

Piscataway, NJ 08854-8019

(732) 445-5185 (phone)

madey@physics.rutgers.edu

Dr. Thomas M. Orlando

Pacific Northwest National Laboratory

P.O. Box 999, MSIN K8-88

Richland, WA 99352

(509) 376-9420 (phone)

Thomas.Orlando@pnl.gov
Dr. Peter E. Haustein

Brookhaven National Laboratory

P.O. Box 5000

Upton, NY 11973

(516) 344-4340 (phone)

haustein@bnldag.ags.bnl.gov

Dr. James P. Cowin

Pacific Northwest National Laboratory

P.O. Box 999, MSIN K8-88

Richland, WA 99352

(509) 376-6330 (phone)

jp.cowin@pnl.gov

\section{Collaborators}

Dr. Nikolay G. Petrik, All-Russian Project and Research Institute of Complex Power Technology, St. Petersburg

Prof. Jory Yarmoff, Dept. of Physics, University of California, Riverside

Prof. R. Dobrozemsky, Dept. of Physics, Technical University of Vienna, Austria 


\section{Specific DOE Problem}

The project addresses several major DOE/EMSP science needs for the Spent Nuclear Fuel Focus Area: 1) stabilization of spent nuclear fuel, including mechanism of pyrophoricity and combustion parameters for various fuel types, 2) characterization of spent nuclear fuel,

3) development of methods to remove moisture without damage to fuel elements, and

4) characterization of corrosion, degradation, and radionuclide release mechanisms, kinetics, and rates for fuel matrices.

\section{Research Objective}

The purpose of this project is to deliver pertinent information that can be used to make rational decisions about the safety and treatment issues associated with dry storage of spent nuclear fuel materials. In particular, we will establish an understanding of: 1) water interactions with failed-fuel rods and metal-oxide materials 2) the role of thermal processes and radiolysis (solid-state and interfacial) in the generation of potentially explosive mixtures of gaseous $\mathrm{H}_{2}$ and $\mathrm{O}_{2}$, and 3) the potential role of radiation-assisted corrosion during fuel rod storage.

\section{Research Progress and Implications}

Interaction of water vapor with $\mathrm{UO}_{2}(001)$ was studied by using low-energy electron diffraction (LEED), x-ray photoelectron spectroscopy (XPS), low-energy ion scattering (LEIS), and electron-stimulated desorption (ESD). LEED and LEIS measurements were carried out at Rutgers University and PNNL. XPS and ESD experiments were done at the EMSL facility at PNNL. ESD measurements of clean $\mathrm{UO}_{2}$ indicate the desorption of $\mathrm{H}^{+}$and $\mathrm{O}^{+}$; the kinetic energy distribution of the latter peaks at $3.5 \mathrm{eV}$. The $\mathrm{O}^{+}$desorption threshold is at $25 \mathrm{eV}$ and is correlated to the ionization of the oxygen 2 s level. LEIS, XPS, and ESD results indicate that adsorbed water is completely dissociated on $\mathrm{UO}_{2}(001)$ at $300 \mathrm{~K}$ and that $\mathrm{O}$ atoms are incorporated into the surface. The results also suggest diffusion of oxygen into the bulk.

A high-vacuum chamber has been designed for the experiments with K-West Basin fuel samples being conducted in the radiation-controlled area of PNNL. The new facility is equipped with a low-energy (5-500 eV) electron gun, a high-resolution focused ion gun, and a secondary electron detector and mass spectrometer. This allows secondary electron microscopy imaging, secondary ion mass spectroscopy, and ESD of spent fuel samples from the K-West Basin.

Gamma radiation-induced degradation of water on oxide particle/water interfaces was studied. Thirty powdered ultrapure $(>99.99 \%)$ crystal oxides were examined. According to the radiation-chemical yield, the oxides can be generally classified into three groups: 1) inhibitors, which lower the $\mathrm{H}_{2}$ yield, 2) indifferent oxides, and 3) $\mathrm{ZrO}_{2}$ and some other oxides that increase the $\mathrm{H}_{2}$ yield more than the radiolysis of pure gas-phase water. A mechanism is proposed for the adsorbed water radiolysis on the $\mathrm{ZrO}_{2}$ surface, based on the migration of excitons to the surface and their resonant coupling with the $\mathrm{H}_{2} \mathrm{O}$ adsorption complex. 
Time- and energy-resolved laser-stimulated luminescence (LSL) measurements were used to investigate the dynamics of electronic excitations in $\mathrm{ZrO}_{2}$. We observe LSL from the decay of three excited states, 2.70, 2.27, and $2.10 \mathrm{eV}$. The emission kinetics are hyperbolic for all the luminescence bands, which indicates a recombination mechanism. We suggest that recombination primarily involves electrons trapped at intrinsic and extrinsic defect sites and mobilized holes.

The breakdown of zirconia films (important to the integrity of Zr-alloy fuel-rod cladding) under extreme radiation conditions has been systematically studied using low-energy electron and photon bombardment of well-characterized $\mathrm{ZrO}_{2}$ surfaces. These studies have clarified the mechanism of oxygen removal from such surfaces. This involves ionization of cation core levels, followed by interatomic auger decay resulting and rapid ejection of $\mathrm{O}+$ ions.

\section{Planned Activities}

We will submit a renewal proposal to 1) characterize major forms of water physically and chemically bonded to major components of the real SNF samples, 2) investigate radiationinduced gas generation and surface degradation on real SNF samples, cladding and rubble materials containing residual bounded water, and 3) complete the development of a predictive model for the radiolytic gas release from the surface of SNF and other components during "dry" storage.

\section{Information Access}

1997-1998 Progress Report. Available URL: http://apollo.osti.gov/em52/1998projsum/ 60392.pdf

1998-1999 Progress Report. Available URL: http://apollo.osti.gov/em52/1998projsum/ 60392.pdf

EMSP Workshop, July 1998 Project. Available: http://apollo.osti.gov/em52/1998projsum/ 60392.pdf

Haustein P. 2000. "Nuclear stimulated desorption studies of oxides relevant to spent fuel material." J. Nucl. Mater. (in preparation).

Hedhili MN, BV Yakshinskiy, and TE Madey. 2000. "Interaction of water with $\mathrm{UO}_{2}$ (001)." Surf. Sci. 445:512-525.

Petrik NG, AB Alexandrov, AI Vall, and TM Orlando. "Gamma radiolysis of water on oxide surfaces: Parameters controlling the energy transfer." J. Phys. Chem. B (in preparation).

Petrik NG, AB Alexandrov, T.M. Orlando, and A.I. Vall. 1999. "Radiation-induced processes at oxide surfaces and interfaces relevant to spent nuclear fuel storage." Trans. ANS 81,101. 
Petrik NG, DP Taylor, and TM Orlando. 1999. "Laser-stimulated luminescence of yttria-stabilized cubic-zirconia crystals." J. Appl. Phys. 85:6770.

Shutthanandan V, S Thevuthasan, and TM Orlando. 2000. "Hydrogen-damage interactions in yttrium stabilized zirconia." J. Nucl. Mater. (in preparation).

Simpson WC, WK Wang, JA Yarmoff, and TM Orlando. 1999. "Photon- and electronstimulated desorption of O+ from zirconia." Surf. Sci. 423:225.

Taylor DP, WC Simpson, K Knutsen, MA Henderson, and TM Orlando. 1998. "Photonstimulated desorption of cations from yttria-stabilized cubic $\mathrm{ZrO}_{2}$." Appl. Surf. Sci. 101:127-129.

Thevuthasan S, SI Yi, YJ Kim, TT Tran, GS Herman, V Shutthanandan, SA Chambers, CHF Peden, and TM Orlando. 2000. "Surface structure determination of $\mathrm{Y}-\mathrm{ZrO}_{2}(001)$ using mass separated recoil spectroscopy and x-ray photoelectron diffraction." Surf. Sci. (in preparation). 